\title{
IMAGENS E PALAVRAS NA CONSTRUÇÃO DE FATORES DE AMBIENCIA QUE CONSIDEREM A ACESSIBILIDADE INTEGRAL NAS ARQUITETURAS DE ACOLHIMENTO DE CRIANÇAS E ADOLESCENTES EM SITUAÇÃO DE VULNERABILIDADE
}

\author{
DISCHINGER, Marta (1); \\ SAVI, Aline Eyng (2) \\ (1) Universidade Federal de Santa Catarina, PhD. \\ e-mail: martadischinger@gmail.com \\ (2) Universidade Federal de Santa Catarina, Mestre \\ e-mail:arquiteta.alinesavi@gmail.com
}

\begin{abstract}
RESUMO
O ECA criou formas de atendimento às crianças e adolescentes em vulnerabilidade social, entre elas: o abrigo. Este não isola, salvaguardando: saúde, educação e moradia; assiste ambos os sexos, entre zero e dezoito anos, em processo ou não de adoção. A institucionalização deveria ser transitória, mas leva meses ou anos. A legislação controla o atendimento, mas é generalista quanto ao espaço, sem considerar fatores de ambiência, entre eles a acessibilidade integral. $O$ artigo visa identificar essas características, sob o olhar das crianças e dos adolescentes, com vistas de garantir a interação entre espaço e pessoas.
\end{abstract}

Palavras chave: abrigo institucional; ambiência; acessibilidade integral

\begin{abstract}
The ECA created forms of care for children and adolescents in social vulnerability, among them: shelter. This does not isolate, safeguarding: health, education and housing; assists both sexes, between zero and eighteen, in process or not of adoption. Institutionalization should be transient, but it takes months or years. The legislation controls the attendance, but it is generalist regarding space, without considering ambience factors, among them an integral accessibility. The article aims to identify these characteristics, sobbing children and adolescents, with a view to ensuring interaction between space and people.
\end{abstract}

Keywords: institutional shelter; ambience; integral accessibility

\section{INTRODUÇÃO}

A aprovação do Estatuto da Criança e do Adolescente (ECA) - lei n 8.069 de 13 de julho de 1990 - e posteriormente, da lei n 12.010 de 03 de agosto de 2009 - "Lei da Adoção" promoveram mudanças no atendimento à infância e adolescência brasileira, com o objetivo de assegurar a proteção integral, com desenvolvimento físico, psicológico e social pleno. Por isso, as grandes instituições, como as Febems, foram descartadas e criaram-se várias modalidades de assistência, a partir dos critérios que ocasionam a institucionalização; entre 


\section{$\prod_{1}^{\text {eneac }}$}

elas: a medida de acolhimento que se divide em: casa de passagem, abrigo institucional, casa lar e república.

A medida de acolhimento assiste crianças e adolescentes de ambos os sexos, com ou sem família de origem ou estendida, em processo ou não de adoção, entre zero e dezoito anos incompletos. Não implica em reclusão e salvaguarda o direito à saúde, educação, moradia e alimentação. O motivo para a institucionalização é variado, mas se relaciona ao quadro de vulnerabilidade social. O período de internação máximo é de dois anos, podendo se estender, se as razões que levaram à institucionalização não forem resolvidas.

Dentre as modalidades existentes, o abrigo institucional corresponde ao maior percentual de instituições no cenário brasileiro e atende cerca de quarenta e sete mil crianças e adolescentes. Deste número, pouco mais de sete mil estão aptos judicialmente à adoção, segundo pesquisa do Cadastro Nacional de Adoção (CNA) e do Cadastro Nacional de Crianças e Adolescentes Acolhidos (CNCA), realizada em 2017. O abrigo institucional diferese, em regra geral, das demais modalidades de acolhimento, por atender até vinte internos num mesmo ambiente.

Os motivos para a realidade brasileira de muitas internações e poucas crianças e adolescentes aptos para a adoção são variados, mas tem o cerne na dificuldade de articulação das políticas públicas para atender integralmente as famílias em situação de vulnerabilidade social. Dessa maneira, a maioria das crianças e dos adolescentes vive rotinas de idas e vindas nas instituições ou ainda, permanecem meses ou anos nesses estabelecimentos. A vivência num abrigo institucional torna-se então, parte da história de vida de cada interno e o ambiente em que se vive, o cenário.

Nesse sentido, a legislação brasileira é bastante generalista e restritiva acerca do ambiente construído. Há apenas: o artigo 92 do ECA; as normas federais: "Orientações Técnicas: Serviços de Acolhimento para Crianças e Adolescentes" (2009) e o "Plano Nacional de Promoção, Proteção e Defesa do Direito de Crianças e Adolescentes à Convivência Familiar e Comunitária" (2006); e os códigos de obras municipais. Toda essa abordagem é quantitativa e limita-se a relação entre números de usuários versus as áreas, os recursos mínimos a serem atendidos, salubridade e higiene. Atualmente, a maioria dos abrigos institucionais tem sedes alugadas e adaptadas ao uso. Acredita-se que essa situação de provisoriedade almejada pela legislação brasileira para a situação judicial de acolhimento institucional, seja um dos motivos para que não haja reflexões mais profundas sobre 0 ambiente construído dessas instituições. Por outro lado, é a realidade de longa permanência (rotinas de idas e vindas, meses e anos internados) que justifica a necessidade de estudar a situação também sob esse viés.

Mesmo sabendo que a história de crianças e adolescentes não deve ser construída com a vivência em instituições de acolhimento, esses estabelecimentos ainda são necessários na realidade social brasileira. É iminente a necessidade de refletir sobre as construções desses estabelecimentos, esperando que a arquitetura contribua para que as instituições não repitam (mesmo que sem intenção) práticas históricas assistencialistas ou com fortes características de reclusão e isolamento. Afinal, o objetivo estabelecido pelo ECA ao abrigo institucional, é de acolhimento individual e em pequenos grupos, subentendendo personalização e privacidade.

Para alcançar esta concepção de qualidade do acolhimento, uma das visões possíveis é estudar o ambiente construído a partir da sua ambiência. $O$ estudo das ambiências relaciona características sensíveis do lugar (como sons, cheiros, luzes e cores) e também, recursos de privacidade e território (tão presentes no habitar doméstico), além da "sua capacidade de evocar memórias e estabelecer afetos" (DUARTE, 2016, p. 72). A acessibilidade integral na arquitetura, torna-se um dos fatores de ambiência a medida que entende o acesso e a realização por parte das pessoas no ambiente construído, abrangendo questões políticas, culturais e sociais. Nos abrigos institucionais, seria permitir que crianças e adolescentes 


\section{remen $^{-1}$}

pudessem vivenciar a permanência institucional conforme a rotina do habitar doméstico, mesmo sendo ele provisório.

Este artigo é parte da discussão da tese de doutorado do Programa Pós-graduação em Arquitetura e Urbanismo (PósARQ) da Universidade Federal de Santa Catarina. Nele, é apresentado um dos procedimentos metodológicos utilizado para a avaliação do ambiente construído e cujo objetivo foi: detectar e descrever as necessidades espaciais sob o olhar das crianças e dos adolescentes internos; para então, propor algumas recomendações projetuais com ênfase na acessibilidade integral, viabilizando a ambiência qualitativa.

O estudo de caso escolhido é um abrigo institucional localizado em município que corresponde à segunda posição (médio porte) no universo com maior número de instituições, segundo pesquisa apresentada por De Assis e Farias (2013). Justifica-se o estudo porque as condições do ambiente construído podem constituir fatores de risco ou de saúde e o contexto ambiental, onde a criança e o adolescente crescem e se desenvolvem, é crucial nas causas e manifestações dos problemas, especialmente nas questões de comportamento. Dessa maneira, o abrigo institucional como substituto, provisório ou não, da estrutura física de casa e psicológica de família, precisa oferecer condições de qualidade para o usuário participar e interagir, desenvolvendo novas competências cognitivas e sociais, especialmente porque os principais usuários estão em processo de crescimento e desenvolvimento de seus corpos e mentes.

\section{REFERENCIAL TEÓRICO}

Habitar uma casa constitui o arquétipo mais rico de significados ao ser humano. É símbolo de todas as "peles" que o envolvem: o seio materno, a família e o universo. "Estar em casa" significa dispor de uma ambiência que, por um lado, se pode assinalar com uma marca e, por outro, delimita um território inviolável sobre o qual se exerce um direito (FISCHER, 1994). Heidegger (2002) afirma que: na privacidade desse ambiente físico recortado do exterior, cada pessoa se recolhe, preserva-se e se desenvolve. Norberg-Schulz (1985, p. 89) completa: "Uma vez cumprida nossa tarefa social, nós nos recolhemos de volta em nossas casas para recuperarmos nossa identidade pessoal. A identidade pessoal é, portanto, um componente do habitar doméstico".

Essa ação é modelada pelas "leituras" que as pessoas fazem e o entendimento marca a diferença entre considerar o ambiente construído apenas pelas suas representações objetivas, ou analisa-lo como elemento maior no contexto, assumindo a influência das diferenças e experiências individuais, bem como das construções sociais de significado. Dessa maneira, o ambiente observado não necessariamente corresponderá ao real e objetivo. Assim, através do olhar institucional, o abrigo pode ser percebido como uma habitação digna às crianças e adolescentes, porque nela há as condições mínimas para sua habitabilidade; mas na visão dos internos pode ser inadequado, porque faltam propriedades físicas, que os reportem às suas casas de origem.

O conjunto de qualidades que fazem de um lugar, por exemplo, o "nosso lar", constitui a ambiência desse domínio. Pode-se afirmar, que ela é revelada no processo de apropriação humana do espaço arquitetônico, envolvendo a interação recíproca entre ambos, na qual cada o homem age no sentido de moldá-lo segundo suas necessidades e desejos; enquanto o ambiente construído torna-se receptivo. Essa influência mútua entre homem/ambiente construído é a razão pela qual se encontra ou não a identidade onde se vive (MALARD, 1993). O termo ambiência tem origem do francês "ambiance" e pode ser traduzido como meio ambiente, sendo composto pelo conjunto de fatores do meio material onde se vive, e também imaterial. Segundo Malard (1993), a ambiência ocorre na relação das pessoas com os objetos funcionais e também, se encontra nas condições de conforto do ambiente construído. 
Cada ambiente construído é constituído cotidianamente por uma ambiência própria, dada por muitos fatores visíveis (materiais) e invisíveis (imateriais) que definem sua identidade, influenciando o comportamento das pessoas que vivem no local ou o percorrem (ELALI, 2009). Ela é composta por aspectos físicos, culturais, sociais, de uso e de temporalidade (THIBAUD, 2004). Cada um desses atributos compõe o espaço dimensionado e funcional, resultando no ambiente construído e determinando o nível de bem-estar de seus ocupantes. Há, porém, valores que são adquiridos culturalmente, de acordo com a experiência de vida, estabelecendo significados, positivos ou negativos, em relação aos estímulos do ambiente (BESTETTI, 2014).

A qualidade dos ambientes construídos destinados à abrigos institucionais, deve considerar a acessibilidade integral. Essa é uma visão de projeto que desenvolve objetos, ambientes e edificações levando em consideração a diversidade. $O$ conceito de acessibilidade está relacionado aos conceitos de inclusão social e de cidadania (SANTOS, 1987). A arquitetura aborda a princípio, a acessibilidade espacial que significa chegar a algum lugar de forma independente, segura e com um mínimo de conforto; entender a organização e as relações espaciais que este lugar estabelece; e participar de todas as atividades que ali se desenvolvem fazendo uso dos equipamentos disponíveis. Ela depende das condições ambientais de acesso à informação, das possibilidades de deslocamento e de uso, e da organização das atividades permitindo participar e estabelecer relações com as demais pessoas.

Nos abrigos institucionais, a busca pela acessibilidade integral deve estar presente no ambiente construído, ajudando a construir ambiências humanizadas. A criança ou o adolescente institucionalizado, devido a suas condições psicológicas e físicas, chega ao abrigo apreensivo, numa mistura de sensações de expectativa, ansiedade, desconfiança, insegurança, desânimo, tristeza e medo. Geralmente, essa pessoa fragilizada é atendida por profissionais que precisam assistir na proporção de um para seis internos e o trabalho tornase estressante e cansativo. Esse estresse pode ser agravado ou amenizado pelas condições do ambiente construído, proporcionada entre outros, por soluções de acessibilidade integral.

Nas soluções de ambiência do ambiente construído, a arquitetura pode colaborar para minimizar efeitos de desconforto, que nos abrigos institucionais, costumam estar relacionados à ambientes frios e impessoais. Para que a ambiência possua qualidade, dessa maneira seja humanizada, deve-se prever ambientes de descanso, tranquilidade relaxamento, que permitam aos internos maior confiança e sentimento de identidade e pertencimento. Além disso, o projeto arquitetônico precisa prever maior rendimento, produtividade e segurança aos profissionais no desempenho de suas atividades.

Nessa visão, as características espaciais que influenciam o comportamento das pessoas não são de análise meramente cartesiana, a partir de condicionantes físicas do ambiente construído. O conceito associa o corpo em movimento, suas expressões motoras, seus percursos sensoriais e cinestésicos e sua capacidade de sentir, sendo influenciado por afetos e sensações na busca de identificação e apropriação com os ambientes construídos (COHEN; DUARTE; BRASILEIRO, 2010). A ambiência é o que possibilita esse processo comunicativo de identidade e pressupõe o espaço arquitetônico como cenário onde se realizam relações sociais, políticas e econômicas de determinados grupos, sendo uma situação construída coletivamente e que inclui as diferentes culturas e valores.

Consequentemente, para investigar a ambiência é necessário incluir uma abordagem sensível, com enfoque qualitativo. Afinal, ela funciona como um agente de ligação entre as diversas sensações experimentadas pelos usuários em uma dada situação (PINHEIRO, 2004). O estudo da ambiência torna-se, assim, imprescindível para a validação dos discursos pautados na experiência sensível com os ambientes construídos e na produção de projetos igualmente vinculados ao valor humano. As ambiências representam o ambiente 


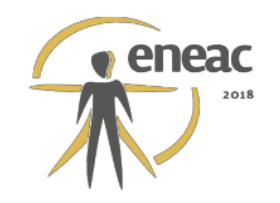

arquitetonicamente organizado e animado, que constitui um meio físico e, ao mesmo tempo, meio estético e psicológico, especialmente preparado para o exercício de atividades humanas - que por sua vez constroem um processo dinâmico de interpretação dos espaços (DUARTE; PINHEIRO, 2013).

\section{PROCEDIMENTO METODOLOGICO}

Na pesquisa, os estudos de fatores de ambiência, entre eles a acessibilidade integral para qualificação dos ambientes construídos de abrigos institucionais, baseiam-se na aplicação conjunta de vários conhecimentos teóricos e procedimentos metodológicos para alcançar dados sobre o homem e as suas relações com o ambiente em que vive, visando melhor adaptá-lo. Utiliza-se uma abordagem holística para responder aos desafios de criar ambientes comprometidos com a valorização e a promoção do desenvolvimento das múltiplas dimensões humanas. Para tanto, a obtenção dos dados exigiu a aplicação do Jogo de Imagem e Palavras. O instrumento é descrito resumidamente nos parágrafos seguintes.

Para superar a dificuldade de verbalização dos abrigados e assim, obter informações de fonte primária (crianças e adolescentes internos), foi aplicado o instrumento metodológico: Jogo de Imagens e Palavras, desenvolvido pelo arquiteto argelino Saddek Rehal (2002). O Jogo consiste na reflexão das idéias dos participantes sobre suas experiências de vida e o que é possível mudar e/ou melhorar nos ambientes por eles vivenciados. Utilizam-se imagens (fotografias, ilustrações e/ou gravuras) para auxiliar os participantes na expressão de sentimentos e na discussão do assunto abordado. A aplicação possui três etapas: na primeira, são feitas perguntas instigantes ao grupo e relevantes ao tema; na segunda, os participantes escolhem as imagens que possuem relação com a pergunta lançada; e na terceira, respondem às indagações referentes ao porquê das escolhas feitas (REHAL, 2002). Durante o método, as falas são gravadas, para serem tratadas por análise de conteúdo.

A série de imagens foi escolhida em meio eletrônico, impressa em versão colorida, colada em papel tipo cartão com dimensões postais. As imagens evocavam diferentes propriedades espaciais cuja função era a ambiência como num habitar doméstico, entre as propriedades estavam questões de acessibilidade espacial, como: acesso a ambientes e mobiliário; diferentes tipos de usuários; autonomia das crianças em atividades domésticas, etc. Reiterase que todas possuíam o habitar doméstico como "cenário" e cada imagem foi classificada em quadros de uso particular dos pesquisadores, incluindo uma "leitura prévia" da "história contada" e destacando as propriedades espaciais mais evidentes. Na aplicação do instrumento, essa leitura não foi apresentada aos participantes, servindo apenas de material de apoio para o gerenciamento dos debates.

O início do Jogo de Imagens e Palavras foi com a pergunta: "Qual dessas imagens lembra o que vocês fazem aqui?". Os participantes escolheram as imagens em grupo, separando-as em duas pilhas, uma onde a imagem recordava a instituição e outra onde não havia ligação. Posteriormente, houve perguntas e debates mediados pelos pesquisadores. As imagens que geraram maior discussão entre os participantes e aquelas que foram prontamente descartadas, tornaram-se objetos de maior indagação. O objetivo foi compreender o que atraiu e repeliu os participantes. As perguntas utilizavam como roteiro a leitura prévia dos pesquisadores (Quadro 01). 


\section{Quadro 01: Leitura prévia das imagens utilizadas no Jogo de Imagens e Palavras.}

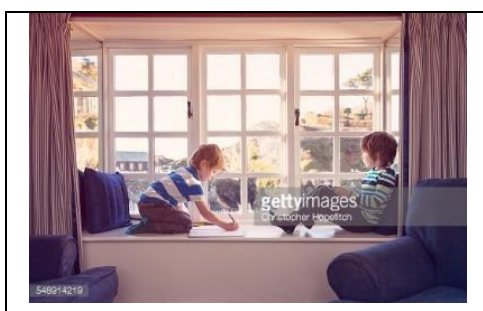

Fonte: Christopher Hopefitch, $2017^{1}$.
Leitura: Acessibilidade espacial e autonomia das crianças, Ambiente: social ou íntimo; Atividade: em conjunto, relativa calma, Predomínio de cores claras; Espaço de convívio - espaço físico congruente espaço de convívio; Cobertura envolvente - Nicho infantil - Variação de pé-direito; Ambiente junto a janela - Janela saliente para a rua Nicho de luz - Abertura natural - Luz natural interna - Vistas orientação solar para o espaço externo

As respostas foram gravadas, transcritas e tratadas por análise do conteúdo, com adaptação dos procedimentos de Bardin (2004) na etapa denominada por ele, de pré- análise. A adequação ocorre porque o autor (2004) trabalha os dados de maneira quantitativa e o objetivo nessa pesquisa é recolher impressões dos usuários sobre o ambiente construído em que vivem e que idealizam para então, sobrepor tais informações com os demais métodos utilizados, servindo de justificativa de ordem qualitativa às leituras realizadas. Após ser realizada a pré-análise, os tópicos de maior abordagem foram apresentados como resultados (Quadro 02). Ressalva-se que o tratamento das informações obtidas é de caráter interpretativo, sem o objetivo de realizar generalizações.

Quadro 02: Tratamento dos dados no Jogo de Imagem e Palavras.

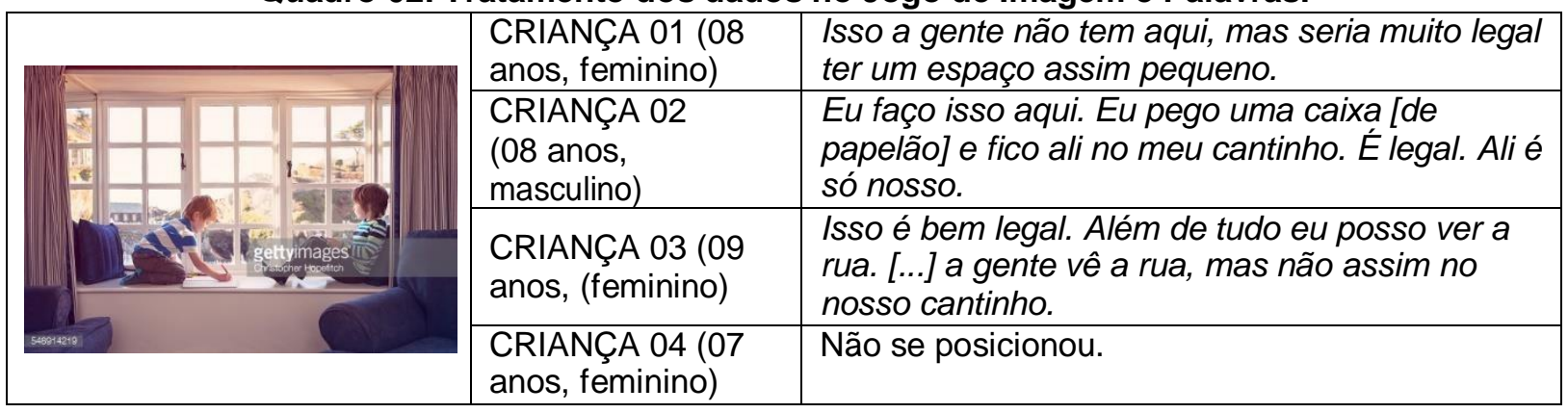

\section{SUGESTÕES E RECOMENDAÇÕES}

A atividade foi realizada com dois grupos, sendo no primeiro o predomínio de crianças e no segundo, de adolescentes. Na aplicação 01, com crianças de ambos os sexos, as preferências faziam alusão ao compartilhamento e predomínio de ambientes com variedade de cores; o desagrado referia-se à proporção de pessoas, à dimensão do ambiente (muito cheio ou vazio), à monocromia do ambiente e também, ao isolamento. Na aplicação 02 , com adolescentes do sexo feminino, os motivos para escolha estavam relacionados aos gradientes de intimidade (do isolamento ao coletivo) e ao uso de cores. Por outro lado, as razões para rejeição indicaram imagens de atividades domésticas ou ambientes excessivamente organizados e/ou monocromáticos.

Sobre o mobiliário e equipamentos, constatou-se a escolha de imagens onde a ergonomia permitiu autonomia nas atividades, inclusive domésticas. Além do predomínio da cor e das texturas como representação do habitar doméstico e em alusão à diversidade e ao uso, como citado anteriormente. "Gostei disso. Aqui até temos a nossa cama e uma prateleira, mas seria legal que fosse bem certinho separado. Cada um com a sua parte" (ADOLESCENTE 06). "Amarelo é bonito e chama atenção. Fica muito bonito na sala. A gente podia ter mais cores aqui também. Aqui é tudo igual" (ADOLESCENTE 07). 


\section{(x) $^{\text {reace }}$}

Os resultados obtidos destacaram a importância das crianças e dos adolescentes sentiremse em casa ou, pelo menos, num modelo de habitar doméstico. Uma das maneiras é viabilizar ao ambiente construído os recursos para participação da rotina doméstica, através de acessibilidade espacial. Essa sensação de lugar e aconchego é criada pela disponibilidade de possuir objetos pessoais com algum significado. É importante que se permita a propriedade individual, que haja locais próprios e de fácil acesso para que esses objetos sejam depositados.

Outro fator importante de autonomia é a cozinha. Ela deve ser um ambiente para promoção de sociabilidade, com possibilidade das crianças e dos adolescentes participarem da rotina da instituição, desde que disponham de condições físicas e psicológicas. Assim, recomendase que o layout e o mobiliário prevejam a participação nessas atividades, principalmente no preparo das refeições e na limpeza do ambiente.

Para incluir as crianças e os adolescentes na rotina e assim, permitir que (re)construam vínculos afetivos com as pessoas e o lugar em que vivem. É importante que, além da acessibilidade plena, haja espaço físico para que os adolescentes auxiliem as crianças em atividades de higiene pessoal, refeições (com a possibilidade de todos sentarem numa mesma mesa) ou atividades escolares. Em contrapartida, é importante que haja espaços internos (no quarto ou num canto da sala, por exemplo) ou externos (um banco sob uma árvore) para que o abrigado escolha a permanência só ou em grupo, evitando a coletividade.

Nos quartos, é fundamental que se incentive a realização de outras atividades além de repousar. Porque o quarto é um dos primeiros territórios de domínio da criança e do adolescente. No abrigo institucional, é o ambiente no qual a coletividade pode ser menos latente. Para isso, é importante que haja mobiliário que permita a apropriação e personalização com objetos pessoais. Evitando a padronização, é interessante que os cômodos tenham cores e decoração variadas, conforme o sexo e a faixa etária.

Para evitar que se estipulem horários rigorosos para a higiene pessoal, os banheiros devem ser divididos por sexo e compartimentados, com o vaso sanitário separado da pia. A privacidade é desejada, mas a vigilância é necessária porque usar o toalete, por exemplo, é uma prática recém-aprendida pela maioria dos abrigados. Assim, devem ser instalados recursos (exemplo: portas curtas nas cabines sanitárias) que permitem ao adulto 0 monitoramento das atividades. Nos banheiros, os cuidados com a acessibilidade permitirão ainda, que um adulto auxilie uma criança durante a higiene pessoal. Cuidados referentes à dimensão infantil e adulta também devem ser tomados, para aumentar a independência dos abrigados e diminuir a carga sobre os funcionários e o risco de acidentes.

O setor social deve ter organização espacial bem definida, segundo as preferências dos internos pelas imagens do Jogo. Isso pode ocorrer com os acabamentos, objetos e mobiliário. Por exemplo, com o piso colorido na área de brincar; na área de refeições, pela disposição das mesas e cadeiras; na de entretenimento, com os sofás ou outros móveis, como prateleiras cheias de brinquedos e livros. Assim, o setor social é integrado, mas as atividades são facilmente reconhecidas, e os abrigados definem os seus lugares preferidos no ambiente mais coletivo do abrigo.

Registra-se também, que dentro do universo de usuários dos abrigos institucionais, o ambiente construído deve responder às particularidades que envolvem as variáveis de condições físicas e psíquicas. É importante prever ambientes construídos com diferentes escalas ergonômicas e respostas para as inteligências múltiplas - linguísticas, lógica, musical, corporal, espacial, naturalista, interpessoal (social) ou intrapessoal (individual), e existencial - que só se desenvolvem em espaços com características específicas.

Nesse sentido, o mobiliário favorece a interação dos usuários quanto possui escalas e proporções que acompanham o desenvolvimento físico de seu usuário, tornando-se assim, 


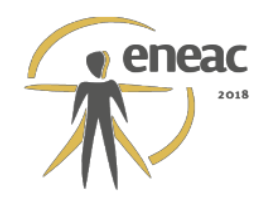

um bom instrumento para o desenvolvimento inclusive de atividades lúdicas no caso das crianças e dos adolescentes. É importante então, prever um mobiliário que atenda às intenções de ambientes integrados com diferentes usos simultâneos; e que seja adaptável às várias transformações da criança e do adolescente. Considerando que alguns internos permanecem longos períodos institucionalizados ou ainda, fazem o processo de idas e vindas, recomenda-se a adoção de tamanhos diferentes de mobiliários - pequeno, médio e grande -, a fim de que sejam atendidos os requisitos básicos de postura para a realização das diversas atividades. A adoção de um único padrão, através de médias de estaturas não é uma solução adequada pois sacrificará a postura daqueles com menor estatura, normalmente em faixas etárias mais baixas, período crítico para a boa formação postural do indivíduo; além de prejudicar o sentimento de pertencimento e autonomia.

A acessibilidade espacial está inserida na aplicação dos conceitos do Desenho Universal (D.U.), requisitos fundamentais para a vivência de um indivíduo em um ambiente público ou privado. O conceito deve ser parte integrante da concepção de projeto e não encarado apenas como mera adaptação. Para equiparar nas possibilidades de uso, deve-se utilizar elementos arquitetônicos que permitam o acesso ao ambiente para o maior número de pessoas, com diferentes possibilidades de circulação (e.g. rampas e escadas); promoção de privacidade e segurança em espaços íntimos com equipamentos de auxílio como barras de apoio ou alarmes e campainhas de emergência; além de permitir fácil legibilidade e recursos para evitar acidentes como amortecedores em portas e janelas.

O projeto deve ainda, considerar a diversidade antropométrica ao detalhar mobiliário e elementos arquitetônicos, considerando as normas vigentes (NBR 9050/2015). Os ambientes construídos devem ter dimensões e espaços de uso de forma a abrigar confortavelmente o usuário, estabelecendo quais elementos do campo visual são importantes, esteja a pessoa em pé ou sentada; as distâncias que precisam ser percorridas sem muito esforço físico; e os espaços que comportam a passagem de pessoas com o auxílio de outras, por exemplo em cadeira de rodas ou carrinhos de bebês.

O sentido de acolhimento é também, atribuído à autonomia dos internos nas atividades do cotidiano e consequente acessibilidade espacial. Dessa forma, desde que aptos para tal função e desejosos de executa-la, é importante incluir as crianças e os adolescentes nas ações de manutenção do abrigo institucional. Um fator que auxilia é a utilização de mobiliário ergonômico e de locais para armazenamento de objetos individuais. Os recursos estimulam a posse, apropriação e consequente, sentido de pertencimento ao lugar, o que levará ao sentimento de sua preservação. Há ainda, o sentido de preparar os internos mais velhos para o desligamento da instituição, quando completam a maioridade. Sugere-se então, o acesso irrestrito à cozinha, com infraestrutura suficiente e adequada, além do monitoramento passivo. O envolvimento direto na organização pode ser facilitado pela utilização de móveis e divisórias leves e fáceis de manusear.

\section{CONSIDERAÇÕES FINAIS}

As necessidades de mudança de cunho social, político, cultural, etc. na realidade dos abrigos institucionais mostraram-se evidentes, mas enquanto isso não ocorre, é fundamental trabalhar na melhoria dos abrigos institucionais, para que sejam minimizadas as consequências maléficas da institucionalização no desenvolvimento e na história de vida dos abrigados. Ressalva-se que esse melhoramento não excluiu o recado inesquecível considerado antes da pesquisa e confirmado na sua conclusão - que uma instituição, seja ela qual for e quão bem equipada e preparada esteja, não é lar permanente para crianças e adolescentes; mas provisório, de permanência excepcional e muito breve.

Os ambientes construídos com poucos fatores de ambiência, incluindo a acessibilidade espacial, contribuem, muitas vezes, para o aumento da agressividade e de outros tipos de 


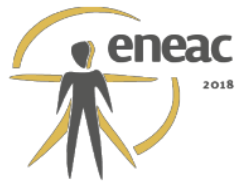

estresses que agravam ainda mais os problemas físicos e psicológicos que acometem as crianças e os adolescentes internos.

Para a promoção de ganhos psicossociais e o resgate (ou construção) dos vínculos afetivos, é preciso, entre outros fatores, que os ambientes se adéquem às necessidades funcionais e psicológicas dos abrigados. Para isso, é preciso identificar que o papel principal dos abrigos institucionais é: viabilizar às crianças e aos adolescentes a interação com pessoas, objetos e símbolos, com um ambiente interno - habitar doméstico - e externo - sociedade e cidade - receptivo e acolhedor. Porque a impossibilidade de vivenciar o espaço da mesma forma que quaisquer outras pessoas, representa uma barreira à acessibilidade integral, aumentando do caráter de segregação social.

Ainda, a aplicação do instrumento metodológico no estudo de caso, permitiu a constatação de que as políticas de atenção às crianças e aos adolescentes devem atentar para a estrutura física das entidades de atendimento. Não somente no sentido de medir a eficiência dos metros quadrados construídos ou do valor agregado das benfeitorias espaciais, mas prevendo que o ambiente ideal para acolher provisoriamente crianças e adolescentes abrigados pode ser encontrado onde cada indivíduo tem espaço para desenvolver as atividades comuns à sua faixa etária e para se expressar. Afinal, essas instituições são substitutas na falta da família e respondem analogamente, porque (re)formam os valores de cidadania.

\section{REFERÊNCIAS BIBLIOGRÁFICAS}

BARDIN, Laurence. Análise de conteúdo. Lisboa: Edições 70, 2004. 223 p.

BESTETTI, Maria Luísa Trindade. Ambiência: espaço físico e comportamento. In: Revista Brasileira de Geriatria e Gerontologia, Rio de Janeiro, 2014; 17(3): 601-610 p.

BRASIL. Lei no 12.010, de 3 de agosto de 2009. Dispõe sobre adoção; altera as Leis nos 8.069, de 13 de julho de 1990 - Estatuto da Criança e do Adolescente, 8.560, de 29 de dezembro de 1992; revogam dispositivos da Lei no 10.406, de 10 de janeiro de 2002 - Código Civil, e da Consolidação das Leis do Trabalho - CLT, aprovada pelo Decreto-Lei no 5.452, de 10 de maio de 1943; e dá outras providências. Brasília, DF: Presidência da República. 2009a.

Ministro do Desenvolvimento Social e Combate à Fome. Secretaria Especial dos Direitos Humanos. Orientações Técnicas: Serviços de Acolhimento para Crianças e Adolescentes. Brasília, DF: 2009b.

Presidência da República. Secretaria Especial dos Direitos Humanos. Conselho Nacional dos Direitos da Criança e do Adolescente. Plano Nacional de Promoção, Proteção e Defesa do Direito de Crianças e Adolescentes à Convivência Familiar e Comunitária. Brasília, DF: CONANDA, 2006.

Estatuto da Criança e do Adolescente: Lei federal no 8069, de 13 de julho de 1990. Dispõe sobre o Estatuto da Criança e do Adolescente e dá outras providências. Rio de Janeiro: Imprensa Oficial. 1990.

COHEN, Regina; DUARTE, Cristiane Rose; BRASILEIRO, Alice. O Acesso Para Todos À Cultura E Aos Museus Do Rio De Janeiro. In: Atas do I Seminário de Investigação em Museologia dos Países de Língua Portuguesa e Espanhola, Volume 2, pp. 236-255. 2010.

DE ASSIS, Simone Gonçalves; FARIAS, Luís Otávio Pires (orgs.). Levantamento nacional das crianças e adolescentes em serviço de acolhimento. São Paulo: Hucitec, 2013. 367p.

DUARTE, Cristiane Rose de S. A empatia espacial e sua implicação nas ambiências urbanas. In: 


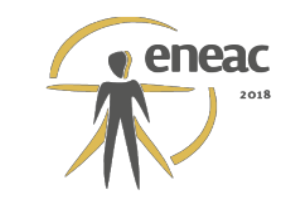

Revista PROJETAR - Projeto e Percepção do Ambiente. Edição Especial de lançamento, v. 1, n.1, abril, 2016. $68-74$ p.

; PINHEIRO, Ethel. Imagine uma tarde chuvosa... pesquisas sobre ambiência, alteridade e afeto. In: Anais do 6 Projetar. O Projeto como Instrumento para a Materialização da Arquitetura: ensino, pesquisa e prática. Salvador, nov. 2013.

ELALI, Gleice Azambuja. Relações entre comportamento humano e ambiência: uma reflexão com base na psicologia ambiental. In: Anais do Colóquio Ambiências Compartilhadas. Rio de Janeiro: ProArq - UFRJ, 2009.

FISCHER, Gustave-Nicolas. Psicologia social do ambiente. São Paulo: Perspectivas Ecológicas, 1994. $216 \mathrm{p}$.

HEIDEGGER, Martin. Ser e tempo. 12. ed. Petrópolis, RJ: Vozes; Bragança Paulista, SP: Universidade São Francisco, 2002. 598 p.

MALARD, Maria Lúcia. Os objetos do quotidiano e a ambiência. 1993. In: $2^{\circ}$ Encontro Nacional de Conforto no Ambiente Construído, Anais do $2^{\circ}$ ENCAC. Florianópolis: ANTAC, ABERGO, SOBRAC, 1993.

NORBERG-SCHULZ, Christian. The Concept of Dwelling: On the Way to Figurative Architecture. New York: Electa/Rizzoli, 1985. 140 p.

PINHEIRO, Ethel. A Cidade no Fragmento: lugar e poiesis no Largo da Carioca. Dissertação de Mestrado. Rio de Janeiro: Proarq/FAU/UFRJ, 2004.

REHAL, Saddek. Words and images for exploration and communication of concepts in the early stages of the design task. In: PROCEEDINGS OF PDC 2002 AT MALMÖ. Editors Binder, T., Gregory, J., Wagner, I.. Malmö, 2002.

THIBAUD, Jean-Paul. O Ambiente Sensorial das Cidades: Para uma abordagem de ambiências urbanas. In: Tassara, E. T. O; Rabinovich, E.P.; Guedes, M. C. (Eds.) Psicologia e Ambiente. São Paulo: Educ. 2004. 